\title{
THE EFFECTIVENESS OF USING WIZIQ INTERACTION PLATFORM ON STUDENTS' ACHIEVEMENT, MOTIVATION AND ATTITUDES
}

\author{
Dr. Abdelrahman Mohamed AHMED \\ ORCID: 0000-0001-6576-9791 \\ Instructional and Teaching Technology Department \\ Sultan Qaboos University \\ Muscat, OMAN \\ Dr. Mohamed Eltahir OSMAN \\ ORCID: 0000-0003-0806-1978 \\ Instructional and Teaching Technology Department \\ Sultan Qaboos University \\ Muscat, OMAN
}

Received: 11/02/2019 Accepted: 04/04/2019

\begin{abstract}
The purpose of this study was to assess the effects of using WiziQ platform as a virtual classroom on students' achievement, motivation and attitudes. The sample of this study consists of 42 students enrolled in the course of "Educational and Information technology" at the college of education, Sultan Qaboos University. The participating students were assigned randomly to a control and experimental group (17 and 25 students respectively). Data collection tools included: an academic achievement test, motivation scale and attitude scale. The results of the study showed that there is a significant difference in the mean scores of the post-test between the control group and experimental group in favor of experimental group. The results also indicated that students in the experimental group developed positive attitude towards using WiziQ virtual classroom in their learning. In addition, the findings showed that students in the experimental group were more engaged and motivated to learn compared to their counterparts in the control group.
\end{abstract}

Keywords: Academic achievement, WiziQ platform, e-learning, motivation, attitude.

\section{INTRODUCTION}

The emerging digital media and internet technologies are impacting the instructional and learning systems more than ever before. There is a plethora of research indicating that these technologies have added value to traditional classroom environments, and consequently changed the students' learning needs, and the approaches of teaching and learning (Gedera, 2014; Bonk \& Graham, 2006; Keller, 2008). Learning Management Systems (LMS), for example, have various attributes and tools that can be used to broaden teaching and learning experiences. These LMSs are used to create online learning environments for campusbased students and also to offer mixed mode and fully online courses (Dilani, John \& Wright, 2013). Currently many universities integrate Learning Management Systems in their teaching processes and utilize blended learning to some of their courses in response to the diverse needs of today's learners. There is a growing body of literature that highlights pedagogical innovations that foster higher-order thinking and enhance opportunities for active learning (Arum \& Roska, 2010; Taylor, 2010). These innovations represent an ongoing paradigm shift from a teacher-centred to learner-centred learning environments (Barr \& Tagg, 1995).

Recent developments in distance learning technologies and associated pedagogical innovations have shown promising potential for synchronous instruction and live classroom interaction to remote students via live virtual classrooms (Falloon, 2011). These technologies, for example, can provide access to suites of interactive tools such as 'virtual whiteboards' and concurrent file sharing streamed video and audio attributes, and at the same time allow students to interact in real-time through text-based chat (Hrastinski, 2008). However, research on the attributes of virtual classrooms in e-learning is limited and inconclusive. This study aims to examine the effects of WiZiQ as a virtual classroom on students' achievement, motivation and attitudes toward using virtual learning environments. 


\section{LITERATURE REVIEW}

Although distance education is increasingly becoming a viable alternative in higher education institutions, it is noted that most of the global initiatives have been asynchronous in nature Hrastinski (2008). However, with recent developments in hardware, software, and relevant communications tools, there exists a great potential for synchronous instruction and classroom interaction via live virtual learning environments. According to Falloon (2011), synchronous components have been present in many online courses for a number of years through text-based chat functionality. Research has shown that the integration of Learning Management Systems (LMS) in Higher Educational settings can often enhance teaching and learning experiences. According to Coates, James \& Baldwin (2005), E-learning platforms such as Moodle, WIZIQ, Blackboard and Docebo offer powerful tools that provide course administration and pedagogical functions such as synchronous and asynchronous communication tools; content development and delivery; assessment and management of students' activities. Smirnova \& Deutsch, (2014) state that online learning through course management systems provides learners with opportunities to become self-directed lifelong learners. According to Dilani, John \& Wright (2013), the available tools and features of e-platforms, improve learners' engagement and consequently enhance their achievement and motivation.

The following section highlights and synthesizes current literature that of particular relevance to e-platforms and their associated theoretical ground.

\section{E-learning Platforms (WIZIQ \& MOODLE)}

Research has shown that the effectiveness of the e-platforms, however, depends largely on their accessible tools and attributes (Coates, James \& Baldwin, 2005; Dilani, John \& Wright, 2013; Smirnova \& Deutsch, 2014). For example; the Moodle e-Learning platform (Modular Object-Oriented Dynamic Learning Environment) is a free open-source learning management system or e-Learning platform, which serves to help educators create online courses with a focus on interaction and collaborative construction of content. It is the most widely used LMS in the world and currently has over 68 million users world-wide (MOODLE. org, 2018). It has been used in Sultan Qaboos University (SQU) since 2006 as an e-platform for a large number of courses at both undergraduate and postgraduate levels. WiZiQ, on the other hand, is a Web 2.0 platform (Figure 1), which can change the way that teachers and learners collaborate in either synchronous or asynchronous mode (Bosatn, 2011). This platform allows the participants to interact through text, audio, and video in a semi-live virtual classroom environment (Davis, 2005; Stevens, 2007). Course instructors, for example, can conduct online live classes and make use of the various tools and features such as: whiteboard, online PowerPoint, Word presentation, PDF, audio and video conferencing, text chatting, and can also record their classes for a later reference.

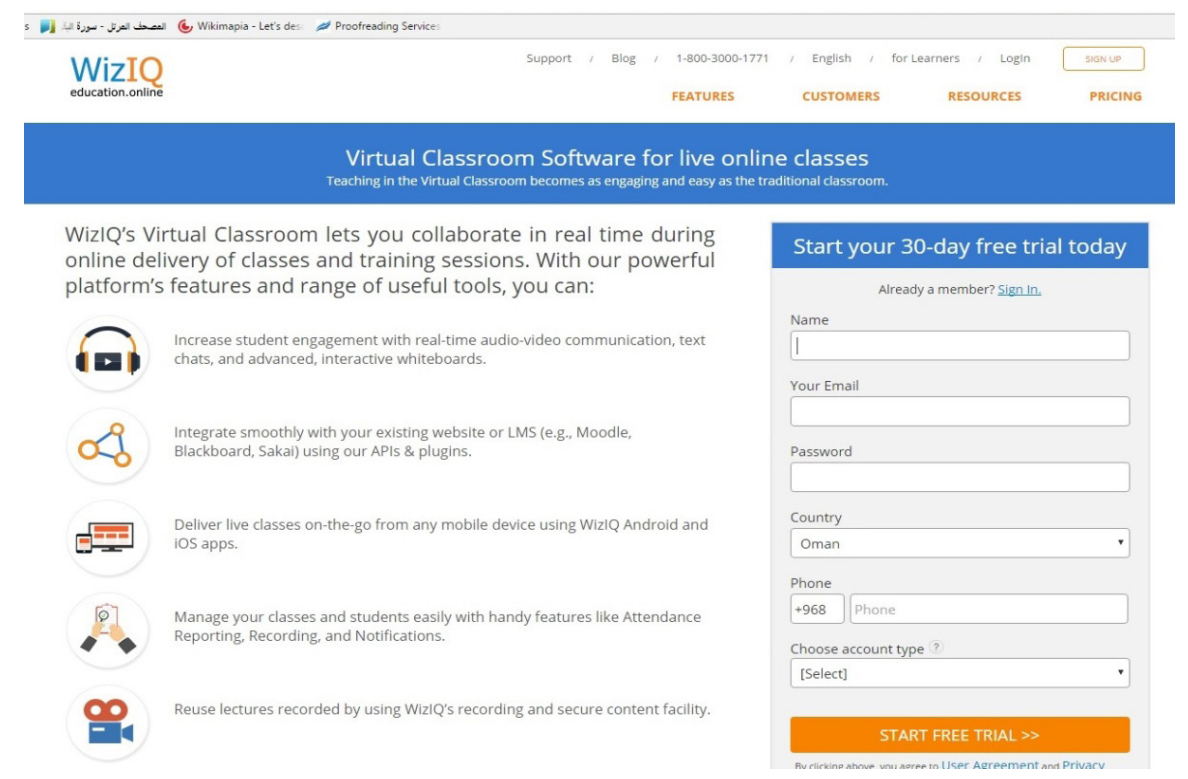

Figure 1. Virtual classroom 
With the evolution of emergent technologies, the synchrony of LMS and Web 2.0 environments have become a powerful combination (Smirnova \& Deutsch, 2014). LMS such as Moodle and WiziQ seem to offer new opportunities for more collaborative learning where students can take control of their learning. These e-platforms provide many services to both teachers and students. Examples of these services include, but not limited to: customizable course design and layout, collaborative activities, learners' engagement, convenient file management, notifications and automatic alerts, multiple progress tracking options, online assessments and feedback, automatic session recording, and cloud-based content library etc. The WiZiQ platform, for instance facilitates students' engagement and interaction in a common virtual space (Stevens, 2007). This space contains a whiteboard with powerful drawing tools, which can be turned into multiple whiteboards for users to upload and share their multimedia presentations.

Research has shown that Web 2.0 technologies, in general could be used to enhance learner engagement and motivation in a more participatory and personalized learning environment (Bostan, 2011). According to Fisher and Baird (2005), Web 2.0 technologies such as WiZiQ platform lead learners from Web content consumers to Web content developers. They further argued that learners are usually more engaged in their learning when provided with collaborative learning environments. However, these participatory environments require a deeper level of social interaction that engages learners in active knowledge acquisition and knowledge construction. Fisher (2012) emphasizes the essential value of e-learning platforms in encouraging collaboration and expanding learning opportunities. Hampel and Pleines (2013) noted that online forums and self assessment activities attracted high participation rates which, interns, improve learners' engagement in their learning processes.

Designing online blended environments, however, requires a careful balance of engagement activities and motivational strategies. Integrated motivational strategies in this study was guided by Keller's ARCS model which has four conceptual components: Attention, Relevance, Confidence, and Satisfaction. The model was developed as an instructional design model to enhance learner's motivation (Suziki, Nishibuchi, Yamamoto, and Keller, 2004).

In addition to the overwhelmingly positive impact on learners' engagement, a number of studies have demonstrated that virtual classroom environments can enhance students' motivation for learning (Capshew, 2005; Chircu and Neacsu, 2015; Colakoglu and Akdemir, 2010; Dikmenli and Unaldi, 2013; Keller, 2008). Durmus and Karakirik (2006) claim that the use of an interactive web-based visual representation of dynamic objects increases not only students' conceptual understanding and problem-solving skills but also promotes positive attitudes towards mathematics, and improves students' motivation. Similarly, previous research has provided strong evidence for the impact of e-platforms on students' attitudes towards virtual classrooms (Penjor and Zander, 2016; Serrano and Sanchez, 2011; Testa (2011). There seems to be a general consensus among researchers that transforming virtual spaces turn the Web into a new area of socialization which consequently promoted students' positive attitudes towards these learning environments.

Previous research, however, has not been conclusive with regard to the impact of virtual classrooms on students' academic achievement. On one hand, for instance, research has shown that virtual classrooms provide conducive learning environments for improved academic achievement (Agrawal, Kumar, Balasubramaniam, Bhargava, Sinha, Bakshi \& Sood, 2016; Barker \& Gossman, 2013; Kaosaiyaporn, Atisabda, Plodkaew, \& Promrak's, 2015; Yilmaz, 2015). Tatli and Ayas, (2013), for example, point out that that virtual laboratories are at least as effective as real laboratories in terms of acquainting students with the experiment processes, and at the same time providing them with a safe experimental environment. While, on the other hand, a number of studies reported no significant differences in students' learning and satisfaction (see for example, Hortos, Sefcik, Wilson, McDaniel \& Zemper, 2013; LeShea, 2013).

In the light of the reported literature, this study aimed to explore the impact of WiziQ as an interactive Web 2.0 platform on students' achievement, motivation and attitudes towards virtual learning environments in a college-level course in educational technology (TECH5001) at Sultan Qaboos University. More specifically, the study aimed to answer the following research questions. 


\section{Research Questions}

1. Is there any significant difference in the mean scores of students' achievement between the experimental and control group?

2. What is the effect of WIZIQ interactive virtual classroom on student attitude towards online learning?

3. Is there any significant difference in the mean scores of students' Motivation between the experimental and control group?

\section{METHOD}

\section{Research Design}

A quasi-experimental design with pre-post control group design was used in this study to investigate the effect of Wiziq as an interactive virtual classroom on students' achievement, motivation, and their attitudes towards online learning.

\section{Study Sample of the Study}

The sample consisted of all students enrolled in the Educational and Information technology course (TECH 5001) at the Department of Instructional and Learning Technologies with a total number of $42(\mathrm{~N}=42)$ students assigned randomly into two groups. The experimental group consisted of 25 students, while the rest of the class (17 students) were assigned to the control group.

\section{Research Instruments}

\section{Achievement test (pre-post test)}

Given the nature of this study, three instruments were used for the data collection: An achievement test, a motivation inventory, and an attitude survey. The achievement test consisted initially of 30 questions (13 multiple-choice questions, 15 true/false questions, and two open- ended questions, with one mark for each). However, the test was validated and modified in light of the referees' comments to include 28 objective questions in its final format. The reliability coefficient of the test was 0.87 .

\section{Motivation Survey (ARCS)}

The study adapted the Instructional Materials Motivation Survey (IMMS) by Keller for assessing students' motivation towards e-learning platform. The survey consists of 36 items: twelve of which for attention, nine for relevance, nine for confidence and six for satisfaction. The (IMMS) administered at the end of the course for the two groups. Alpha Cronach reliability for total survey was 0.91 , and for each dimension of the survey was 0.81 for attention, 0.81 for relevance, 0.67 for confidence and 0.64 for satisfaction. The response scale ranges from 1 to 5 , with a minimum score 36 , and a maximum score of 180 , and a midpoint score of 108. However, it should be noted that the minimum, maximum, and midpoint scores for each subscale vary depending on the number of items in the subscale.

\section{Attitude Questionnaire}

The students' attitudes towards Wiziq online virtual classroom was measured by an attitude questionnaire which consisted of 16 items containing positive and negative statements. The Alpha Cronbach reliability coefficient for the total survey was 0.83 .

\section{Procedures}

All the students enrolled in the "Educational and Information technology" course was randomly assigned to the treatment groups with 25 students in the experimental group studied the course through WIZIQ 
e-learning platform (synchronous engagement). While the other 17 students assigned to the control group who studied through the normal MOODLE e-learning platform (asynchronous collaborative engagement). The duration for experiment in this study was 8 weeks. The two classes had a 4-hour class period every week where both groups were taught the same content by the same instructor.

The WizIQ's virtual classroom used in this study was a collaborative web conferencing environment which enables the instructor to communicate synchronously using audio, video or text chat, interactive whiteboard and content sharing. Figure 2 illustrates a typical classroom layout, with the video/audio, participants' textbased chat, and presenter notes pods being visible. Other pods such as shared whiteboard, polling, desktop, and file sharing were revealed and used, as needed. Figure 3 shows the students' comments on the virtual lecture.

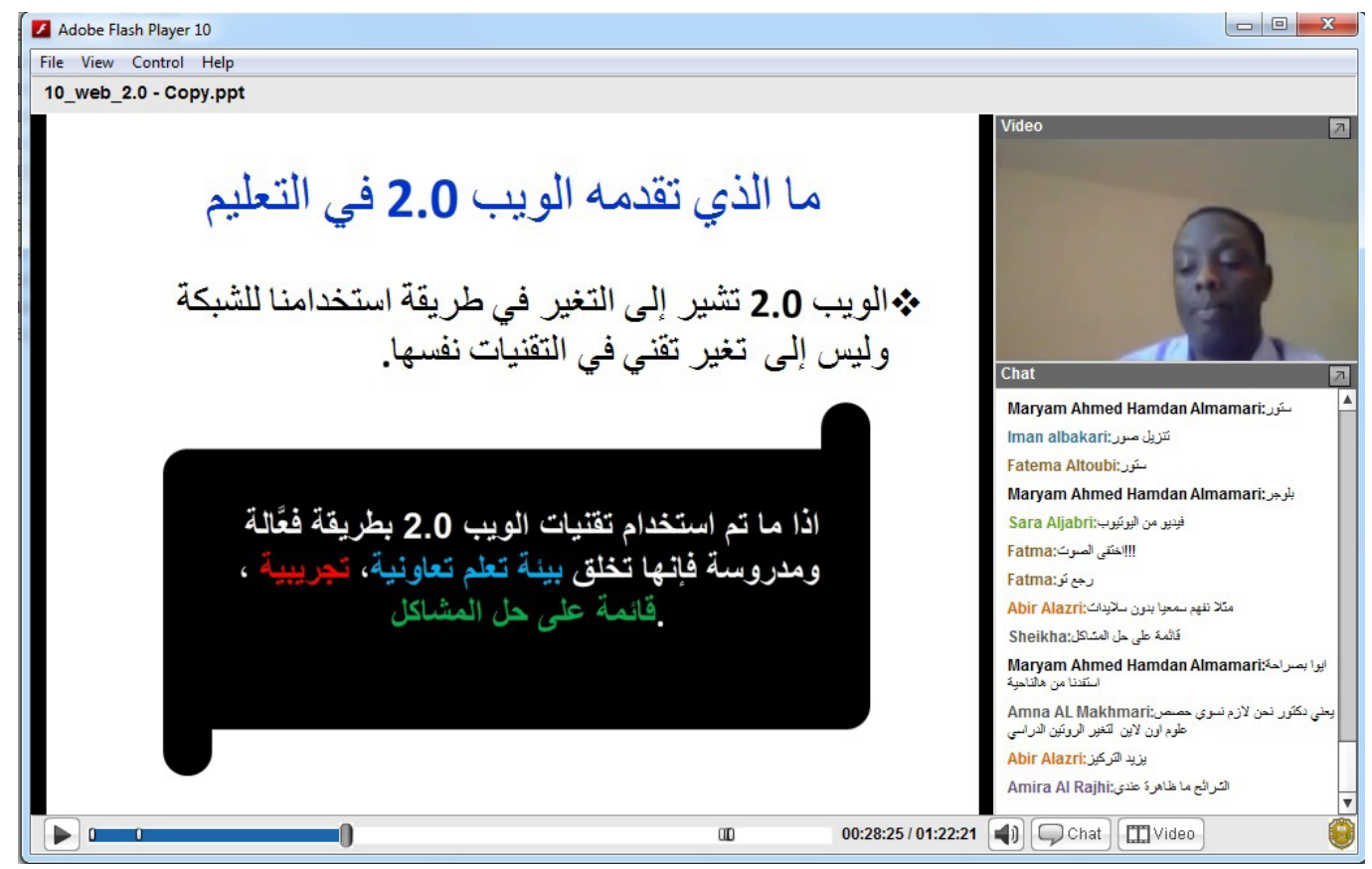

Figure 2. A typical virtual classroom layout

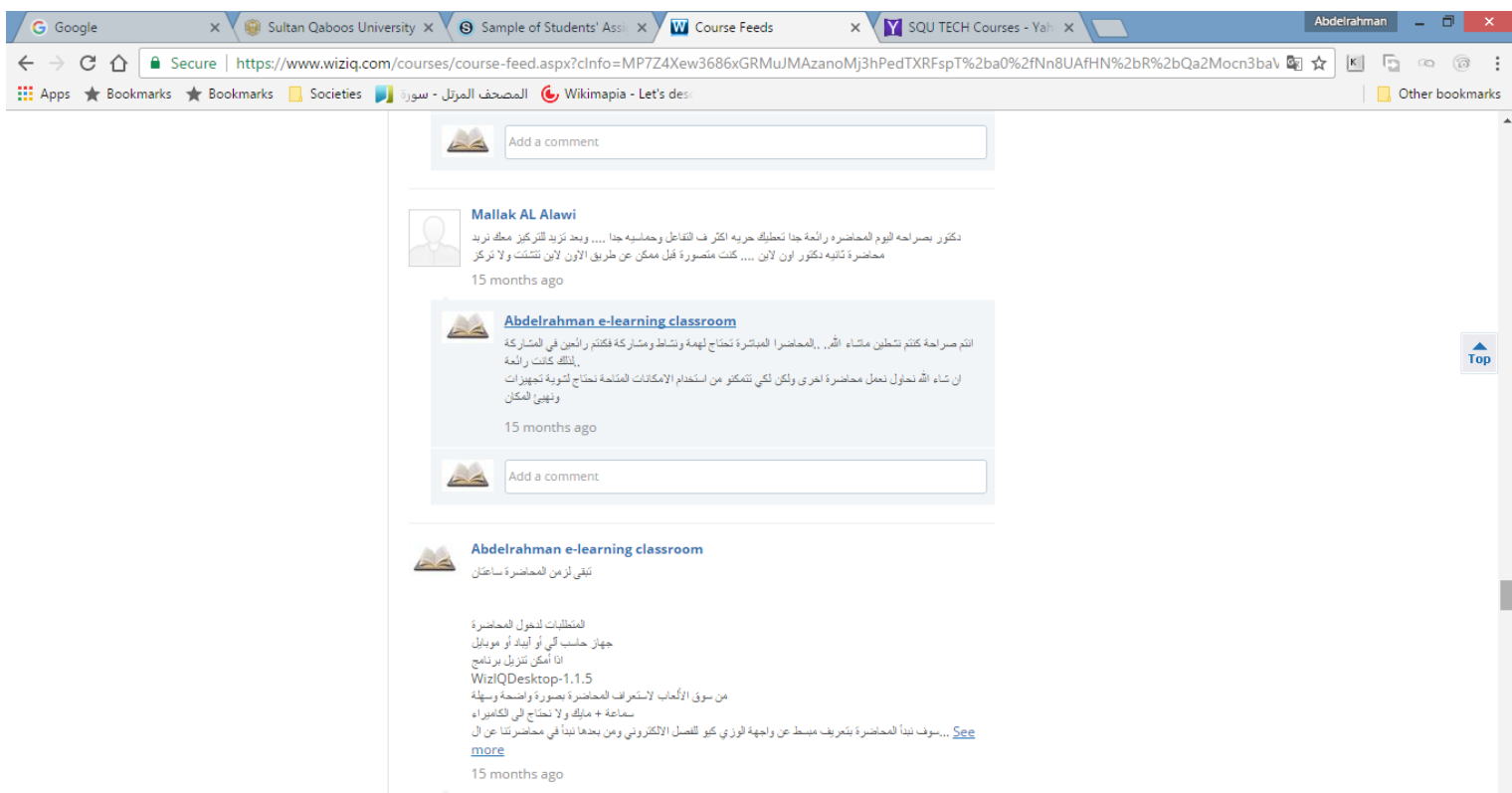

Figure 3. Students' comments on the virtual lecture 
At the end of the experimental treatment, a post-test was administered for both groups to test for students' academic achievement. In addition, an attitude and motivation instruments were also administered at the end of the experiment.

\section{RESULTS}

\section{Academic Achievement}

Before the experiment, the researchers administered a pre-test to ensure the equivalency of the two groups. The mean and standard deviation of the scores were 16.26 and 2.333 for the experimental group, and 17.00 and 1.03 for the control group, respectively. An independent sample t-test was used for testing the mean differences in students' achievement of the two groups.

Table 1. Independent sample t-test scores for differences in the mean scores of the pre-test

\begin{tabular}{lcccccc}
\hline Group & $\mathrm{N}$ & $\mathrm{df}$ & Mean & $\mathrm{SD}$ & $\mathrm{t}$ & Sig. \\
\hline Control & 17 & 40 & 17.00 & 1.03 & 1.226. & .228 \\
Experimental & 25 & & 16.26 & 2.33 & & \\
\hline
\end{tabular}

As indicated in Table 1, no significant difference was observed in students' mean scores between the control and experimental group $(t=1.226, .228, \mathrm{p}>0.05)$. Accordingly, the two groups were considered to be equivalent before the treatment.

\section{Post-Test Achievement}

students' achievement, an independent sample t-test was used to compare means scores of the achievement test for the two groups. Table 2 below shows the mean differences of students' scores in the post test.

Table 2. Independent sample t-test scores for differences in the mean scores of the post-test

\begin{tabular}{lcccccc}
\hline Group & $\mathrm{N}$ & $\mathrm{df}$ & Mean & $\mathrm{SD}$ & $\mathrm{t}$ & Sig. \\
\hline Control & 17 & 40 & 34.11 & 1.10 & 3.003 & .005 \\
Experimental & 25 & & 35.84 & 1.70 & & \\
\hline
\end{tabular}

Table 2 indicates that there is a significant difference in the means scores of the post test between the control group and experimental group $(t=3.003,0.005, \mathrm{p}<0.05)$ in favor of the experimental group. This result could be attributed to the online enrichment activities provided to students in the experiential group, such as students' engagement in real-time learning sessions; practicing online communication skills; using WiziQ online whiteboard; involvement in an online discussion using course feedback; and quizzes. Taken collectively, these interactive activities seem to have a significant impact on students' performance in the post test.

In addition, the collaborative nature of WiziQ tools provided opportunities for students to interact with each other and share their acquire knowledge. This finding is supported by Barker \& Gossman (2013) who used Virtual Learning Environment (VLEs) with similar tools and activities and concluded that VLEs were found to be very effective in improving students' learning. Also, this result is in alignment with that of Agrawal et al., (2016). They reported that virtual classroom was found to be effective in improving students' knowledge and skills. However, this finding contradicts the findings of LeShea (2013) which showed that incorporating live, synchronous class sessions into an online course did not increase students' levels of achievement. It also contradicts Hortos et al's (2013) findings which showed that there were no significant differences between medical students who received their lectures through virtual classroom and those who attended live lectures in medical student preparedness or academic achievement. Nevertheless, the impact of VLEs on students' performance depends largely on the attributes of VLEs and the nature of interactive tools being utilized. 


\section{What is the Effect of WiziQ Interactive Platform on Student Attitude towards Online Learning?}

In order to answer the research question related to students' attitudes, a questionnaire was used to assess their attitudes towards online learning. The descriptive statistics for each of the 16 items assessed using a five-point Likert scale of the students' attitudes towards WiziQ online learning virtual classroom are presented in Table 3. The overall result indicates that students had a positive attitude towards online learning using WiziQ virtual classroom (mean=3.75).

Table 3. Mean scores of students' attitudes towards online learning using WiziQ virtual classroom?

\begin{tabular}{|c|c|c|c|}
\hline Statement & $\mathrm{N}$ & Mean & SD \\
\hline WiziQ learning platform is worthwhile. & 18 & 4.61 & .50 \\
\hline I have a desire to learn a lot about e-learning platform WiziQ. & 18 & 4.56 & .51 \\
\hline $\begin{array}{l}\text { I feel that WiziQ learning platform encourage me to participate in the classroom } \\
\text { discussion. }\end{array}$ & 18 & 4.44 & .62 \\
\hline I think it is important for me to learn to use different learning platforms. & 18 & 4.39 & .61 \\
\hline I think that WiziQ learning platform help to motivate students for learning. & 18 & 4.33 & .59 \\
\hline I feel that I am a competent WiziQ learning platform user. & 18 & 4.3 & .78 \\
\hline WiziQ learning platform do not scare me at all. & 18 & 4.22 & .94 \\
\hline I do not feel intimidated by a learning platform. & 18 & 4.22 & .43 \\
\hline I feel that there is a definite need for WiziQ learning platform in the classroom. & 18 & 4.06 & .73 \\
\hline I feel confident using different learning platforms. & 18 & 3.94 & .54 \\
\hline My training on WiziQ learning platform is adequate. & 18 & 3.89 & 1.08 \\
\hline I think that WiziQ learning platform help students to collaborate with each other. & 18 & 3.78 & .81 \\
\hline $\begin{array}{l}\text { The challenges of learning about new ways of engaging students by using technology } \\
\text { are exciting to me. }\end{array}$ & 18 & 3.56 & .98 \\
\hline I am not the type that does well with WiziQ learning platform. & 18 & 1.89 & .68 \\
\hline I avoid using WiziQ learning platform as much as possible. & 18 & 1.89 & .32 \\
\hline Working with WiziQ learning platform makes me very nervous. & 18 & 1.83 & .62 \\
\hline Total & 18 & 3.75 & .24 \\
\hline
\end{tabular}

Table 4. Students' attitudes towards online learning using WiziQ platform One-sample test

\begin{tabular}{ccccccc}
\hline \multirow{2}{*}{ Students' attitudes score } & $\mathrm{N}$ & $\mathrm{df}$ & Mean & $\mathrm{SD}$ & $\mathrm{t}$ & Sig. (2-tailed) \\
\cline { 2 - 7 } & 18 & 17 & 3.75 & .28 & 66.918 & .001 \\
\hline
\end{tabular}

More specifically, table 3 shows that 9 out of 16 statements had high mean scores ranging between (4.06 - 4.61). The top six statements of the positive attitudes towards using WiziQ online learning platform as viewed by the students in the experimental group as follows: (a) WiziQ learning platform is worthwhile (mean score 4.61); (b) I have a desire to learn a lot about e-learning platform WiziQ (4.56); (c) ) I feel that WiziQ learning platform encourage me to participate in the classroom discussion (4.44); (d) I think it is important for me to learn to use different learning platforms (4.39); (e) I think that WiziQ learning platform help to motivate students for learning(4.33); and, (f) I feel that I am a competent WiziQ learning platform user (4.3). The results also showed only three statements have a mean score of less than two. These are: I am not the type that does well with WiziQ learning platform (1.89); I avoid using WiziQ learning platform as much as possible (1.89); and Working with WiziQ learning platform make me very nervous (1.83). These results indicated that, students in the experimental group had positive attitude towards using WiziQ online learning platform in their learning. The student's positive attitudes towards online learning could be attributed to the fact that the WiziQ online learning platform allows the learner to interact via text, audio, and video with other participants in a virtual classroom environment (Stevens, 2007). In such environment, instructors can conduct online live classes and make use of various features like: whiteboard, online PowerPoint, Word presentation, PDF, audio and video conferencing, text chat, class recordings for later reference. 
Moreover, as illustrated in table 4 students who use the WIZIQ platform appeared to be more engaged in their learning when provided with collaborative learning environments. They seemed to have developed appositive attitudes towards online learning $(\mathrm{t}=66.918, .001, \mathrm{p}<0.05)$. These findings are in congruence with a number of studies (e.g., Fisher, 2012; Bostan, 2011; Hampel and Pleines, 2013). These studies in general indicate that WiziQ platform seems to encourage collaboration among students and consequently expand learning opportunities. They reported that students had a positive attitude towards the use of online activities as an integral part of a distance language course. It can be concluded that WiziQ learning platform provides a collaborative and enjoyable learning environment for the students which might have positively influenced their attitudes towards the teaching and learning processes.

\section{Students' Motivation}

Is There any Significant Difference in The Mean Scores Of Students' Motivation Between The Experimental And Control Group?

With regard to the effect of WIZIQ virtual classroom on student motivation, an independent sample t-test was used to compare the mean scores of students' motivation in the two groups. 17 student from the control group completed the motivation scale, while only 24 students from the experimental group filled the motivation scale.

Table 5. Independent sample t-test scores for differences in means of the students' motivation

\begin{tabular}{lcccccc}
\hline Group & $\mathrm{N}$ & Mean & $\mathrm{SD}$ & $\mathrm{df}$ & $\mathrm{t}$ & Sig. (2-tailed) \\
\hline Control & 17 & 3.41 & .22097 & 39 & 3.886 & .001 \\
Experimental & 24 & 3.63 & .14217 & & & \\
\hline
\end{tabular}

Table 5 shows that there is significant difference in the mean scores of students' motivation between the control group and experimental group $(\mathrm{t}=3.886, .001, \mathrm{p}<0.05)$ in favour of experimental group. This result could be attributed to the role of WiziQ's teaching tools in providing opportunities for students to collaborate and socialize in an online learning environment. In addition, WiziQ allows for recording entire class sessions for later reference. The recordings can be viewed online or downloaded and distributed offline to the students. Perhaps, it is these dynamic attributes of WiziQ that helped in increasing students' motivation level. This finding is supported by Barker \& Gossman (2013) who reported that the students using Virtual classroom exhibit greater motivation than their counter partners in traditional learning environments.

However, the level of students' motivation varies according to the different dimensions of the ARCS inventory. The following tables $(6,7,8$, and 9) illustrate the mean differences of students' scores in the four dimensions in the ARCS inventory (i.e, Attention, Relevance, Confidence, and Satisfaction, respectively).

Table 6. Independent sample t-test scores for differences in means of the attention dimension of ARCS motivation

\begin{tabular}{lllllllc}
\hline Dimension & Group & $\mathrm{N}$ & Mean & SD & $\mathrm{df}$ & $\mathrm{t}$ & Sig. (2-tailed) \\
\hline \multirow{2}{*}{ Attention } & Control & 17 & 3.50 & .32 & 39 & 2.23 & .03 \\
& Experimental & 24 & 3.69 & .22 & & & \\
\hline
\end{tabular}

Table 6 indicates that there is significant difference in the mean scores of students' attention between the control group and experimental group $(\mathrm{t}=2.23, .03, \mathrm{p}<0.05)$ in favour of experimental group. WiZiQ virtual classroom provides students with opportunities to interact with other participants in a common virtual space. This space contains a whiteboard with powerful drawing tools, which users can turn into multiple whiteboards, and upload PowerPoint presentations. According to Velagapudi (2013) providing students with opportunities to collaborate in sustained active engagement helps in raising students' motivation in general and attention in particular. 
Table 7. Independent sample t-test scores for differences in means of the relevance dimension of ARCS motivation

\begin{tabular}{lllccccc}
\hline Dimension & Group & $\mathrm{N}$ & Mean & SD & df & t & Sig. (2-tailed) \\
\hline \multirow{2}{*}{ Relevance } & Control & 17 & 3.37 & .28312 & 39 & 3.89 & .001 \\
& Experimental & 24 & 3.73 & .28933 & & & \\
\hline
\end{tabular}

With regards to Relevance dimension of students' motivation table7 shows that there is significant difference in the mean scores of this dimension between the control group and experimental group

$(\mathrm{t}=3.897, .001, \mathrm{p}<0.05)$ in favour of experimental group. This means that the group taught by using WiziQ virtual classroom shows high motivation level regarding relevance than their counter partners using the traditional method. This result could be justified by the fact that this learning environment offers opportunities for learners to take more control of their learning processes and engaged in contextually relevant activities.

Table 8. Independent sample t-test scores for differences in means of confidence dimension of ARCS motivation

\begin{tabular}{llcccccc}
\hline Dimension & Group & $\mathrm{N}$ & Mean & SD & df & t & Sig. (2-tailed) \\
\hline \multirow{2}{*}{ Confidence } & Control & 17 & 3.31 & .24699 & 39 & 3.018 & .004 \\
& Experimental & 24 & 3.53 & .22695 & & & \\
\hline
\end{tabular}

Table 8 indicates that there is significant difference in the mean score of the confidence dimension in the motivation inventory between the control group and experimental group $(t=3.018, .004, p<0.05)$ in favour of experimental group. This means that the group taught by using WiziQ virtual classroom shows high motivation level in terms of confidence than their counter partners using the traditional method. This result could be attributed to the fact that the students in experimental group using WizIQ virtual classroom were more able to collaborate in real-time with tools like real-time virtual classrooms with multi-way audio, live video streams, integrated chat, online whiteboard, application sharing, and file transfer which help them build up their confidence level and expectancy towards success in this course.

However, with regards to the Satisfaction dimension in table 9, the result showed that there is no significant difference in the mean scores of students' satisfaction between the two groups $(t=.918, .364, \mathrm{p}>0.05)$.

Table 9. Independent sample t-test scores for differences in means of the satisfaction dimension of ARCS motivation

\begin{tabular}{llcccccc}
\hline Dimension & Group & $\mathrm{N}$ & Mean & SD & $\mathrm{df}$ & $\mathrm{t}$ & Sig. (2-tailed) \\
\hline \multirow{2}{*}{ Satisfaction } & Control & 17 & 3.44 & .20362 & 39 & .918 & .364 \\
& Experimental & 24 & 3.51 & .27766 & & & \\
\hline
\end{tabular}

Although students in general were satisfied with the course content, they appeared to be less satisfied with the type of corrective feedback they received on their performance in the course activities. Perhaps this may have impacted their overall level of satisfaction. This finding seems to be supported by several studies in massive open online courses "MOOCs" (e.g., Huang \& Hew, 2016; LeShea, 2013) who also concluded that students usually were found to be less satisfied with the feedback they received in live synchronous learning environments compared to asynchronous learning environments. 


\section{CONCLUSION}

The purpose of this study was to examine the effects of the virtual classroom by using WiziQ platform on students' achievement, motivation and attitudes. The findings of this study are in congruence with a larch body of relevant literature. The results in general, indicated that WIZIQ can improve not only the students' academic achievement, but also promote their motivation and attitudes towards online learning environments. Furthermore, with regard to the four conceptual components of the ARCS model, the study showed that, there is a significant difference in the mean scores of the attention, relevance and confidence dimension of motivation between the control group and experimental group in favor of experimental group. In addition, the study showed that, students in the experimental group who used WiziQ as a virtual classroom had positive attitude towards online learning. Perhaps the social openness in virtual environments contribute significantly to the improvement of the students' engagement in the learning process, which consequently improve their academic achievement and motivation levels. However, future research might be needed to further explore the effectiveness of the various tools and attributes of WIZIQ as an interactive web-based environment in expanding the learning landscape for the students in different learning settings.

\section{BIODATA and CONTACT ADDRESSES of AUTHORS}

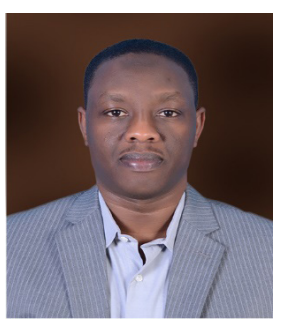

Dr. Abdelrahman Mohamed AHMED, is the Head of Assessment Unit at the College of Education, Sultan Qaboos University. He is also an assistant professor of educational technology, with over 10 years of experience in teaching graduate and undergraduate courses in the areas of instructional design, information and communication technologies, and research in educational technology. His current areas of research include technology integration, Social media, mobile learning, e-learning, distance education, and use of web 2.0 technologies in education.

Abdelrahman Mohamed AHMED

Instructional and learning Technologies Department, College of Education

Address: Sultan Qaboos University, PC123, P.O. BOX 32, Alseeb, S. of Oman

Phone: +96824413798

E-mail: abdoelhaj@squ.edu.om

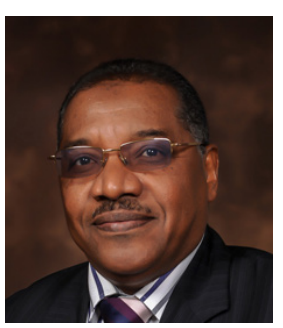

Dr. Mohamed Eltahir OSMAN, is the Head of Instructional and Learning Technologies Department at the College of Education, Sultan Qaboos University. He is also an associate professor of educational technology, with over 20 years of experience in teaching graduate and undergraduate courses in the areas of instructional systems design, information and communication technologies, and research in educational technology. Before taking up his current position, he was previously the Assistant Dean for Postgraduate Studies and Research at the college of education, SQU. Dr. Osman is an Emeritus Board member and Vice President of the International Council of Education for Teaching (ICET) for the MENA region. He has presented and researched extensively on issues related to school improvement, quality assurance, web-based learning environments, human resources.

Mohamed Eltahir OSMAN

Instructional and learning Technologies Department, College of Education Address: Sultan Qaboos University, PC123, P.O. BOX 32, Alseeb, S. of Oman

Phone: +96824413798

E-mail:mosman@squ.edu.om 


\section{REFERENCES}

Agrawal, N., Kumar, S., Balasubramaniam, S., Bhargava, S., Sinha, P., Bakshi, Bh. \& Sood, B. (2016). Effectiveness of virtual classroom training in improving the knowledge and key maternal neonatal health skills of general nurse midwifery students in Bihar, India: A pre- and post-intervention study. Nurse Education Today, (36), pp. 293-297.

Arum, R., \& Roska, J. (2010). Academically Adrift: Limited Learning on College Campuses. Chicago: University of Chicago Press.

Baird, E., \& Fisher, M. (2005). Neomillennial user experience design strategies: utilizing social networking media to support "always on" learning styles. Journal of Educational technology systems, 34(1) 5-32.

Barker, J., \& Gossman, P. (2013). The learning impact of a virtual learning environment: students' views. Teacher Advancement Network Journal, 5(2).

Barr, B., \& Tagg, J. (1995). From teaching to learning: A new paradigm for undergraduate education. Change, $27(6)$, pp. 12-25

Bonk, C., \& Graham, C. (2006). The handbook of blended learning: Global perspectives, local designs. San Francisco: Pfeiffer.

Bostan, G. (2011, April). Teaching/learning physics on Wiziq platform. In The 7 th International Scientific Conference eLearning and Software for Education Bucharest.

Capshew, T. F. (2005). Motivating social work students in statistic courses. Social Work Education. 24(8), 857-868.

Chircu, S., \& Neacsu, I. (2015). Using E-Learning Tools in The Growth of Students' Motivation Regarding Formal Education. The 11th International Scientific Conference eLearning and Software for Education Bucharest, April 23-24, 2015. 10.12753/2066-026X-15-108.

Coates, H., James, R., \& Baldwin, G. (2005). A critical examination of the effects of learning management systems on university teaching and learning. Tertiary Education Management, 11(1), pp. 19-36.

Colakoglu, O. \& Akdemir, O. (2010). Motivational measure of the Instruction compared: Instruction Based on the ARCS Motivation Theory v.s. Traditional Instruction in Blended Courses, Turkish Online Journal Of Distance Education-TOJDE, 11 (2), 1302-6488.

Davis, I. (2005). Talis, Web 2.0 and All That. Accessed on 14 January 2018, Retrieved from: http://blog. iandavis.com//2005/07/talis-web-20-and-all-that. Accessed 20 April 2017.

Dikmenli, Y., \& Unaldi, U. (2013). Effect of the blended learning environment and the application of virtual class upon the achievement and the attitude against the geography course. Mevlana International Journal of Education, 3(2), 43-56.

Dilani, S., John. P. and Wright, N. (2013). An analysis of Moodle in facilitating asynchronous activities in a fully online university course. International Journal of Science and Applied Information Technology (IJSAIT), 2(2), pp.06-10.

Durmus, S., \& Karakirik, E. (2006). Virtual manipulatives in Mathematics education: A theoretical framework. The Turkish Journal of Educational Technology, 5(1). 117-123.

Falloon, G. (2011). Exploring the Virtual Classroom: What Students Need to Know (and Teachers Should Consider). Journal of Online Learning and Teaching, 7(4), pp 439-451.

Fisher, D. (2012). Warming Up to MOOC's. ProfHacker. The Chronicle of Higher Education. Accessed on 13 April 2018, Retrieved from: http://chronicle.com/blogs/profhacker/warming-up-tomoocs/44022

Gedera, D. S. P. (2014). Tool mediation and learner engagement: An Activity Theory perspective. In B. Hegarty, J. McDonald, \& S.-K. Loke (Eds.), Rhetoric and Reality: Critical perspectives on educational.

Hampel, Regine and Pleines, Christine (2013). Fostering Student Interaction and Engagement in a Virtual Learning Environment: An Investigation into Activity Design and Implementation. The CALICO Journal, 30(3) pp. 342-370. 
Hortos, K., Sefcik, D., Wilson, S., McDaniel, J. \& Zemper, E. (2013). Synchronous videoconferencing: impact on achievement of medical students, Teach Learn Med, 25 (2013), pp. 211-215

Hrastinski, S. (2008). Asynchronous and synchronous e-learning. EDUCAUSE Quarterly, 31, 4, 51-55.

Huang, B., \& Hew, Kh. (2016). Measuring Learners' Motivation Level in Massive Open Online Courses. International Journal of Information and Education Technology, 6(10), pp. 759-764. DOI: 10.7763/ IJIET.2016.V6.788.

Kaosaiyaporn, O., Atisabda, W., Plodkaew, J., \& Promrak's J. (2015). Factors of Virtual Classroom to Enhance Online Learning in Multicultural Society for Pre-Service Teacher Students. International Journal of Information and Education Technology, 5(7), pp. 502-506.

Keller, J. (2008). First principles of motivation to learn and e-learning. Distance Education, 29(2), 175-185.

LeShea, A. (2013). The effects of synchronous class sessions on students' academic achievement and levels of satisfaction in an online introduction to computers course. Doctoral dissertation, unpublished, Liberty University.

Moodle Website, accessed on 26 March 2018, Retrieved from: https://moodle.org/,

Penjor, S., \& Zander, P. (2016). Predicting virtual learning environment adoption: A case study. The Turkish Online Journal of Educational Technology, 15(1), 69-81.

Serrano, M. \& Sanchez, M. (2011). Improving Social Interactions in Virtual Learning Environments: Guidance on Spatial Factors for Online Teachers. US-China Education Review, (16), pp. 471-480.

Smirnova, L., \& Deutsch, N. (2014, June). Addressing Contextual Adaptation in the Dissemination of Online Technologies: Using Moodle and WizIQ for Professional Development Training. In EdMedia: World Conference on Educational Media and Technology (Vol. 2014, No. 1, pp. 12051211).

Stevens, V. (2007). Who's in charge here? WiZiQ and Elluminate. The Electronic Journal for English as a Second Language (TESL-EJ), 11(3).

Suziki, K., Nishibuchi, A., Yamamoto, H., and Keller, J. M. (2004). Development and evaluation of a website to check instructional design based on the ARCS Motivation Model. Journal of the Japanese Society for Information and Systems in Education, 2(1), 63-69.

Tatli, Z. \& Ayas, A. (2013). Effect of virtual chemistry laboratory on students' achievement. Educational Technology and Society, 16(1), 159-170.

Taylor, C. (2010). Crisis on Campus: A Bold Plan for Reforming Our Colleges and Universities. New York: Knopf.

Testa, A. (2011). Experiences of Online Learning: An Evaluation of First-year Sport Sciences University Students' Attitudes towards the Use of U-Link. International Education Studies, 4(4), 13-21. doi:10.5539/ies.v4n4p13

Velagapudi, M. (2013). 18 FREE Web 2.0 Tools for Teachers. A publication of WizIQ, Inc. Accessed on 14 January 2017, Retrieved from: https://www.wiziq.com/whitepaper/59-18-free-web-2-0-tools-forteachers/

Yilmaz, O. (2015). The effects of "live virtual classroom" on students' achievement and students' opinions about "live virtual classroom" at distance education. The Turkish Online Journal of Educational Technology, 14(1), pp. 108-115. 